\title{
Autonomia, a tivismo e colaboração: contribuições para o debate sobre a mídia independente contemporânea
}

\author{
Evandro de Assis ${ }^{1}$ \\ Leonel Cama sã o ${ }^{2}$ \\ Mariana Rosa Silva ${ }^{3}$ \\ Rogério Christofoleti4
}

\section{Resumo}

Os últimos a nos têm permitido a emergência de um grande número de iniciativas jomalísticas que se autointitulam "independentes" ou "altemativas". Os rótulos não são novos, mas se percebe que a onda atual tem caracteństicas próprias que contribuem para uma rediscussão de conceitos como autonomia, independência financeira e editorial. Um arranjo que possibilita também tensionar essa importante categoria - a independência - num cenário pós-industrial, onde é crescente a partic ipação efetiva daqueles que antes chamávamos de públicos

\footnotetext{
${ }^{1}$ Especialista em Direção Editorial (ESPM-SP) e mestrando em J omalismo no POSJ OR/UFSC. Sua dissertação trata de meios independentes e critérios editoriais para o uso de conteúdos colaborativos. Pesquisador do Observa tório da Ética Jomalística (objETHOS). Email: evandrodeassis@hotmail.com.

2 Mestrando em Jomalismo no POSJOR/UFSC. Pesquisador do Observatório da Ética J omalística (objETHOS), estuda instrumentos de a ferição da independência jomalística. Email: leonelcamasao@gmail.com.

3 Mestranda em Jomalismo no POSJOR/UFSC e pesquisadora do Observatório da Ética J omalística (objETHOS). Sua disserta ção discute ca racteriza ção e a tua ção de coletivos de mídia independente no cenário contemporâneo. E-mail: rosasilva.mariana@gmail.com.

4 Professor do Programa de Pós-Graduação em Jomalismo da UFSC, onde coordena o Observatório da Ética Jomalística (objETHOS) e orienta as dissertações dos trabalhos a cima mencionados. Pesquisa dor do CNPq. E-mail: rogerio.christofoletti@ufsc.br.
} 
e onde o ativismo contraria valores históricos do jomalismo como o da imparcialidade. Os resultados a que chegamos sinalizam um panorama mais dinâmico para a definição da independência e ajustes necessários para as expectativas que essa ideia exige.

Palavras-chave: Independência jomalística. Ativismo. Partic ipação.

\section{Abstract}

In the last couple of years a great number of emergent joumalistic projects have been calling themselves as "independents" or "altematives". These labels are not new, but the wave we perceive nowadays has its own features which contribute to a rediscussion about concepts such as autonomy, economic and editorial independence. A confomation that also makes it possible to question this important category - the independence - in a post industrial scenario, where the participation of whom we used to call "the audience" grows and where activism contradicts historical values of joumalism such as impartiality. The results we achieve suggest a more dynamic panorama for the definition of independence and suggest some adjustments in order to meet the expectations this id ea requires.

Keywords: Independence of Media; Activism; Partic ipation.

\section{Introdução}

A paisagem midiática contemporânea vem sofrendo transformações rápidas e profundas nas últimas três décadas em todos os mercados. As razões que motivam tais mudanças são variadas, indo de vetores econômicos - identificados nas fissuras e insuficiências do modelo de negócio hegemônico do setor, equilibrado no sistema de publicidade - a tecnológicos - com a digitalização dos processos e o viralizante alastramento das redes informáticas. Os planos econômico e tecnológico tendem a ser os mais vocalizados para explicar o cenário, mas não podem ser ignorados também fatores culturais, ora derivados da adoção de novas tecnologias de informação e comunicação, ora evidenciados a partir da chegada de novos atores na cena.

No primeiro caso, a digitalização de textos, áudios e imagens, a troca de pacotes de informação pela internet, a manutenção de bancos de dados e arquivos em diversas bases, o acesso a fontes por essas mesmas vias, a miniaturização de muitos equipamentos de coleta, registro e produção de conteúdos, e o barateamento de outros gadgets para consumo dessas informações, tudo isso, combinado, levou a alterações de comportamento de jornalistas, comunicadores e públicos. Condições como ubiquidade, 
instantaneidade e multimidialidade transformaram (e continuam a transformar) nossas maneiras de produzir bens simbólicos e a acessá-los.

Paralelamente, os públicos - antes habituados à situação de meros receptores passaram a ter condições técnicas para transpor o muro que os separava dos produtores de informação. Esse potencial desestabilizou uma equação de décadas, e levou as redações e os jornalistas a se reposicionarem diante de um público que não se satisfazia mais em permanecer na posição de audiência.

Em poucos anos, não apenas observamos à ruína de algumas certezas jornalísticas - como a de que só profissionais poderiam produzir informação -, mas também assistimos à emergência de formas variadas de colaboração com os públicos. Muito recentemente temos visto ainda o surgimento de diversas iniciativas jornalísticas que reivindicam um estatuto de independência antes só evocado pela mainstream media e colocando-se como alternativas de informação. Meios independentes ou alternativos não são uma novidade, e já se apresentaram em outros momentos da história. Mas neste artigo discutimos algumas condições que diferenciam os empreendimentos contemporâneos de seus antecessores. De forma oportuna, tensionamos a construção de uma pretensa autonomia às sombras do ativismo e da crescente participação dos públicos nos processos jornalísticos.

\section{Dimensões da autonomia}

Uma das correlações mais frequentes e imediatas é a que distancia jornalismo de política. "Geralmente se equaciona independência e autonomia no jornalismo em relação ao poder do Estado" (LIMA, 2010, p. 113). Tal relação remonta à Idade Média e ao Absolutismo. Em alguns casos, perduram até hoje mecanismos de censura aos meios de comunicação ou de livre acesso à internet, em várias partes do mundo. No caso brasileiro, as organizações tidas como jornalísticas sempre mantiveram algum grau de dependência do Estado, desde o período colonial.

Este tipo de interdependência se materializa por meio de subsídios, empréstimos bancários e financiamentos oficiais; de isenções fiscais, publicidade legal obrigatória ou publicidade oficial e, mais recentemente, até mesmo pela compra volumosa - e sem licitação - de material didático (...). Por óbvio, essa interdependência histórica, muitas vezes fez com que o jornalismo se submetesse aos interesses do Estado, sobretudo nas 
relações da mídia regional e local com os governos estaduais e municipais. (LIMA, 2010, p. 114)

Conforme o autor, quando a própria mídia toca no assunto das liberdades de expressão e de imprensa, o Estado sempre é identificado como único poder que ameaça a autonomia do exercício do jornalismo. Entretanto, a observação de outros autores nos mostra que não é apenas o Estado e nem o impasse do financiamento da atividade jornalística os únicos elementos a se pensar para definir critérios e parâmetros sobre a independência na área.

Para Karppinen \& Moe (2016), o "cabo de guerra" sobre o significado de mídia independente é uma discussão tão antiga quanto a ideia de liberdade de imprensa. Entendida aqui como um conceito relacional, a independência no jornalismo pode ter diferentes significados em distintos contextos, ou ainda, ser apropriada em nome de determinados interesses. Na Europa, o caso mais típico é a maneira como as empresas privadas de comunicação se referem aos serviços públicos de radiodifusão, muito comuns naquele continente. Segundo os autores, o segmento privado refere-se a si próprio como "a mídia independente", enquanto serviços como a BBC ou a RAI seriam a "mídia estatal".

Karppinen e Moe traçam as noções mais comuns ao se falar em independência no jornalismo: ausência de controle ou influência por agentes externos, capacidade de indivíduos ou organizações de tomarem decisões baseados em sua própria lógica, autogoverno, liberdade de administrar seu negócio jornalístico da maneira que convier, ou até mesmo, uma estratégia para ampliar seu público.

O significado da independência da mídia como um valor normativo depende claramente do contexto em que é usado. Muitos discursos e conotações estabelecidos em torno do termo podem, assim, ser rastreados até contextos históricos e culturais específicos onde as organizações de mídia usaram propositadamente a noção para legitimar sua posição. Por exemplo, em países com uma imprensa politicamente alinhada [ao governo], jornais partidários podem declarar sua independência de afiliações políticas históricas, como parte de uma estratégia para ampliar seus leitores de segmentos políticos específicos para um público de massas. (KARPPINEN \& MOE, 2016, p. 107, tradução nossa)

Em um aspecto normativo, independência pode se referir ao que Habermas chamou de "autonomia da esfera pública". Mas o termo também pode ser compreendido como uma maneira de se distanciar da imprensa ou da indústria convencional 
(mainstream). Esse distanciamento se daria não apenas no formato, mas nas práticas e rotinas de produção, um jeito diferente de fazer o jornalismo, onde as regras do mercado e da indústria convencional não aprisionariam a criatividade e a liberdade autoral dos produtores. O termo "indies" (abreviação para independents) também é associado a projetos digitais inovadores, organizações sem fins lucrativos, ou ainda, veículos de comunicação "subversivos" ou contrários ao "sistema". (KARPPINEN \& MOE, 2016). Porém, Hunter (2015) argumenta que a natureza precária do trabalho independente, assim como a falta de estrutura para executar o trabalho, deixa os indies tão ou mais vulneráveis a pressões externas e outros interesses do que os jornalistas formalmente empregados.

Schulz (2015) observa como nas línguas inglesa e alemã o termo independence é construído de forma negativa. No inglês, o prefixo in significa negação (in-dependence), assim como no alemão o prefixo un (Un-abhängigkeit). A construção da palavra em português segue a mesma lógica ("in-dependência"). Nos três casos, a definição de independência é a "não-dependência", ou a ausência de dependência. O autor afirma ser difícil encontrar um sinônimo positivo nas duas línguas (e é igualmente difícil em nosso idioma). Para Schulz, a palavra que mais se aproxima é autonomia (autonomy). Porém, enquanto a primeira impõe uma relação a algo (independente de quem ou do quê?), a segunda estaria mais relacionada a ações e regras.

Este raciocínio contradiz a ideia geral de independência como algo positivo, qualidade que faz o sujeito ou organização serem "melhores" do que aqueles que são "dependentes". Ao refletir sobre a diferença sutil entre independência e autonomia, Schulz propõe visualizar o termo dependência (estar sob controle de) como principal. A partir deste movimento, fica mais fácil pensar a ideia de independência não em relação à autonomia, mas sim, em relação à ideia de controle. A aparente positividade da ideia de independência é contestada pelo autor ao redefinir o conceito não mais como sinônimo de autonomia, mas sim, como ausência de controle. Uma organização totalmente independente, portanto, estaria imune a qualquer controle de agentes externos, sejam eles forças de repressão, órgãos reguladores e a sociedade em geral. A nocividade desta ideia reside num fato simples: por não haver controle algum, por não haver um sistema de regras, limites e eventuais sanções para quem as descumpre, sujeito ou organização totalmente independentes constituem-se, enfim, como atores arbitrários. Podem descumprir regras e não precisam justificar seus atos ou prestar contas a ninguém. 
O mérito da abordagem é a relação dialética que se estabelece entre as ideias de independência e regulação, na medida em que a construção da independência se dá em relação a um sistema de regras e convenções socialmente estabelecidos. Em outras palavras, a validação de uma relativa independência no jornalismo se dá na medida em que um sistema regulatório é eficiente em estabelecer limites claros para combater eventuais arbitrariedades. Neste esquema interpretativo, a independência ou não de determinado objeto poderia ser verificada ao analisar os elementos capazes de causar dependência e autonomia.

Historicamente, questões econômicas, origem do financiamento da atividade, verbas publicitárias, e formas de pressão de anunciantes e acionistas têm efeitos sobre a independência do jornalismo. Bucci (2009) afirma que essas são demandas tão antigas quanto a própria democracia. A independência se articula não só com o exercício do jornalismo enquanto profissão, mas com o direito à informação, previsto em marcos legais do país e no exterior. Daí que o autor mencione "indicadores de autonomia jornalística", que não chega a desenvolver, mas que antevê como possibilidade de pesquisas futuras. Três questões ajudariam a problematizar o tema: Quem paga as contas da publicação? Quem paga os jornalistas? A quem presta contas a redação?

$\mathrm{Na}$ maioria das vezes, o jornalismo sobrevive à custa de verbas publicitárias, financiando a publicação e os profissionais. Da mesma maneira, em termos ideais, os jornalistas prestam contas a seus editores (também jornalistas) e ao público. Assim, a independência se expressaria na transparência com a qual os veículos e os jornalistas expressam seus compromissos (BUCCl, idem).

As características mais visíveis da crise financeira no segmento dos meios impressos - evasão de verbas publicitárias, queda nas tiragens, demissões e extinção de títulos - renovam a discussão sobre independência pois colocam em xeque também fatores essenciais para a subsistência como a credibilidade. É quando os meios passam por dificuldades financeiras que o campo jornalístico visualiza mais claramente as interferências comerciais e políticas nos rumos editoriais. A insolvência leva à negligência.

Tal como uma verdadeira democracia não pode sobreviver ao financiamento da sua vida política por um pequeno número de indivíduos com recursos infinitos, também os média, garantes da qualidade do debate democrático, não podem ser colocados sob a influência exclusiva de milionários com bolsos sem fundo. Daí a necessidade de se pensar, para além do pluralismo dos títulos da imprensa e das cadeias de 
televisão, o pluralismo da propriedade dos media: um conjunto de acionistas múltiplo, diversificado, onde a maioria dos direitos de voto não fique nas mãos de uma minoria de indivíduos (CAGÉ, 2009, p.21).

Se o modelo de sustentação do jornalismo adotado há poucos séculos dá sinais de esgotamento, soluções são apresentadas, como a do financiamento coletivo. A premissa de que "quanto mais financiadores, mais independentes seremos" não está de toda errada. Existem iniciativas que buscam massificar o número de financiadores individuais, envolvê-los em processos de decisão das pautas e acompanhamento das reportagens produzidas, garantindo não uma imparcialidade que existe apenas no discurso, mas uma certa "parcialidade justificada".

A questão do financiamento coletivo como "solução" para o problema da independência no jornalismo tem sido defendida por jornalistas, coletivos e por alguns autores, como Cagé (2009). O princípio da autonomia financeira rege essa concepção. Não havendo anunciantes em determinado produto jornalístico, ou ainda, na ausência de proprietários/acionistas que possam intervir no conteúdo a ser produzido, a autonomia estaria virtualmente garantida. Na prática, a realidade é mais complexa.

De qualquer maneira, o crowdfunding não atrapalha a busca por novos modelos de financiamento do jornalismo desatrelados das verbas publicitárias e governamentais, com fins de maior autonomia. Mas é necessário compreender que, neste momento, ele não resolve por si a questão nem o problema do "modelo de negócio" nem o da independência jornalística. A "parcialidade justificada" nos impele a discutir como autonomia e ativismo se articulam.

\section{Independência e ativismo}

Em diferentes momentos históricos, experiências que se distanciam em maior ou menor medida da concepção convencional de jornalismo se desenvolveram, gerando expressões e leituras distintas da sua atuação. No contexto brasileiro, um caso simbólico no desenvolvimento deste tipo de experiência é a imprensa de resistência ao regime militar nas décadas de 1960 e 1970. Embora publicações de caráter contestador ao discurso dominante na imprensa oficial e nos chamados jornais informativos tenham uma atuação significativa desde os tempos do domínio português, tendo inclusive participação no processo da Independência (BELTRÃO, 1992; BAHIA, 2009), assim como em outros 
momentos políticos marcantes na história do país, é durante a ditadura militar que se adota a expressão "imprensa alternativa", que permanece como referência para tratar esse tipo de experiência a partir daí.

De forma geral, a expressão é usada para situar experiências que se diferenciam de um determinado padrão - de jornalismo, cultura, etc. - e que surgem ligadas a um contexto histórico e cultural específico, como, por exemplo, os fanzines na Inglaterra nos anos 1980 estudados por Atton (2012). Embora seja frequentemente associada a uma postura de ativismo de oposição ao sistema capitalista, a mídia alternativa "não necessariamente significa atividade anticapitalista, antiempresarial ou anti-industrial" (BECKER, 2009). Dois aspectos que, quando levados em conta, tornam difícil a adoção da mesma como um conceito. Afinal, o que confere a uma experiência o status de alternativa em relação a outras? A resposta deve variar de acordo com o contexto em questão - bem como o padrão ao qual se quer contrapor. Sendo assim, especialmente num momento em que o campo jornalístico passa por tantas transformações, o termo acaba por se mostrar um rótulo sob o qual podem se abrigar experiências de natureza distinta.

Uma das principais referências para abordagens nesta temática é Downing, que em 1984 formula a noção de "mídia radical". Em um texto mais recente, Downing (2001) denomina como mídia radical iniciativas feitas em pequena escala de formatos variados que expressam uma visão alternativa às políticas, prioridades e perspectivas hegemônicas. O autor justifica a preferência pelo uso de "radical" em detrimento de "alternativa" tendo em vista que "tudo, em certa medida, é uma alternativa a alguma coisa" (DOWNING, 2001, p. ix). O autogerenciamento dos grupos é um fator central, uma vez que para Downing "a importância da organização coletiva e horizontal na comunicação não reside apenas em alguma noção de pureza ideológica ou teorização antigerenciamento", mas em uma preocupação dos membros em relação às condições políticas e culturais que afetam suas escolhas organizacionais, como observa Atton (2002, p. 99).

Sandoval e Fuchs (2010), que - como Atton - trabalham com a denominação "mídia alternativa", também enfatizam o aspecto do gerenciamento como distintivo das experiências alternativas. Os autores fazem contraponto à ideia corrente da mídia alternativa como mídia participatória (que tem o envolvimento do público), defendendo a ideia de uma mídia crítica que, por sua vez, resulta de uma relação dialética entre os 
estruturas e atores envolvidos no sistema de mídia. Para os autores, a mídia alternativa deve se diferenciar da mainstream nos aspectos estrutural e individual, proporcionando produtos não-comerciais e abrindo o processo de produção à participação dos consumidores.

(a) No nível estrutural, o ideal típico da mídia alternativa difere da mídia de massa capitalista no que diz respeito ao formato econômico dos produtos midiáticos: a mídia alternativa ideal proporciona produtos midiáticos não comerciais no lugar de commodities. Eles também se diferenciam no que diz respeito ao conteúdo e a forma.

(b) No nível dos atores, o ideal típico da mídia alternativa abole a distinção entre produtores e consumidores, todos os consumidores dos produtos da mídia alternativa podem também se engajar ativamente no processo de produção. O prosumer precisa ser crítico no sentido de que ele(a) interpreta o conteúdo de mídia existente e é apto a produzir novo conteúdo midíatico crítico. (SANDOVAL; FUCHS, 2010, p. 145, tradução nossa)

Da mesma forma, Peruzzo defende a centralidade do conjunto da práxis na distinção das iniciativas alternativas, populares ou comunitárias:

Os elementos principais que caracterizam a comunicação como popular,comunitária e/ou alternativa estão no processo, nas práticas sociais, nas relações que se estabelecem, e não no tipo de veículo utilizado, nem em outra característica qualquer (linguagem, propriedade, formato) tomada isoladamente. O que importa é o conjunto da práxis e o significado que tem para a comunidade. (2009, p.140).

Grinberg (1987 apud WOITOWICZ, 2011, online) defende a importância do discurso: "sem discurso alternativo não há meio alternativo". O contrário, no entanto, nem sempre se mostra verdadeiro: um discurso alternativo nem sempre é fruto de uma estrutura radicalmente diferente do padrão, o que pode ser observado sobretudo atualmente, quando nos vemos já distantes dos contextos históricos que deram origem à cultura alternativa e a sua linguagem é ocasionalmente usada como mera roupagem ao jornalismo feito por veículos comerciais que nada trazem de alternativo fora o discurso. Em todas estas perspectivas, como podemos observar, o diferencial do "alternativo" em relação ao "tradicional" está numa postura ativista, seja ela no âmbito estrutural, prático ou discursivo.

Da mesma forma, a noção de "mídia independente" costuma ser relacionada ao ativismo, neste caso, geralmente de forma mais incisiva contra o poder econômico. Trata- 
se, também, de um conceito relacional. Seria necessário perguntar: independência de quem? Nesse sentido, a discussão proposta por Karppinen e Moe (2016), traz uma perspectiva interessante ao situar a mesma enquanto oposição à mainstream media:

Além da independência da autoridade do estado e/ou interesses comerciais, independência também se refere a um modo particular de fazer as coisas que é alternativo à mídia mainstream e a sua lógica. Enquanto oposição dentro do complexo da indústria de mídia, independência, deste modo, vem no sentido de distância "do mainstream", que é visto como refletindo o convencional ou os gostos da massa e restringindo a liberdade criativa. Se a mídia mainstream se apresenta como independente porque segue sua própria lógica de cultura jornalística, para outra mídia independente o mesmo termo significa liberdade em relação à própria noção da cultura jornalística mainstream (KARPPINEN e MOE, 2016, p. 110, tradução nossa).

Desta forma, como prosseguem os autores, a noção de "mídia independente" no contexto contemporâneo pode se referir também ao jornalismo nativo da internet que é financeiramente independente do "legado da indústria de mídia", recorrendo a saídas como o financiamento coletivo (KARPPINEN e MOE, 2016). Nesta perspectiva, a lógica de funcionamento também se destaca como critério em relação ao discurso e, da mesma forma, a questão de fundo é a oposição ao mainstream.

De volta ao contexto brasileiro, a preocupação com uma separação da lógica mainstream parece ser a essência das iniciativas que hoje atuam em paralelo ao jornalismo tradicional.

O Mapa do Jornalismo Independente ${ }^{5}$, publicado pela Agência Pública em março de 2016, lança luzes sobre o perfil dessas iniciativas e identifica cerca de 70 veículos nativos da internet considerados independentes de grandes grupos de mídia, políticos, organizações ou empresas ${ }^{6}$. Diferente da fase da imprensa alternativa de oposição ao

5 Disponível em: http://apublica.org/mapa-do-jomalismo/. Acessado em 9 de abril de 2017.

6 A seleção levou em conta quatro aspectos: (1) organizações que produzem primordialmente conteúdo jomalístico; (2) organizações que nasceram na rede; (3) projetos coletivos, que não se resumem a blogs; (4) sites não ligados a grandes grupos de mídia, políticos, organizações ou empresas. O alinhamento a os critérios estabelecidos foi confirmado a partir de um questionário com as seguintes perguntas: "A sua organização, entidade ou coletivo produz primordialmente conteúdo jomalístico? Possui caráter comercial? Qual é a missão da sua organização? Há quanto tempo a organização 
regime, não há agora uma pauta comum, são projetos nativos da internet, criados entre 1995 e 2015, com propostas diversas que frequentemente se caracterizam pelo ativismo em defesa de causas, valores e compromissos éticos específicos do nosso tempo e também pela adoção de formatos de organização distintos da indústria de mídia, como coletivos e associações sem fins lucrativos, entre outros. Vejam-se os casos da Mídia $\mathrm{Ninja}^{7}$, uma ampla rede de participantes voluntários, e da Revista AzMina ${ }^{8}$, financiada a partir da prestação de serviços.

A presença de uma crítica mais enfática à lógica da indústria de mídia em si também se mostra na própria concepção de algumas destas experiências, como o coletivo Jornalistas Livres $^{9}$, que surge da preocupação de profissionais que não encontravam na grande mídia espaço para publicação de determinadas investigações e da busca por mais autonomia profissional.

\section{A colaboração como fator problematizador}

Se a independência jornalística for compreendida como imunidade total a influências externas, o conceito fica restrito a uma idealização normativa. Por outro lado, se admitida a existência de diferentes intensidades e naturezas de influências, e o pesquisador estiver interessado em compreender a capacidade de um indivíduo ou instituição de tomar decisões e agir conforme sua própria lógica (KARPPINEN e MOE, 2016), abrem-se múltiplas possibilidades de avanço na compreensão das dependências do jornalismo.

Neste sentido, é pertinente pensar o problema também a partir do modelo de hierarquia das influências, proposto por Shoemaker e Reese (2013). Os autores organizam cinco categorias de forças que podem influenciar a produção de informações,

existe? Como a sua organização se mantém? Qual é a figura juńdica? Qual(is) a(s) cidade(s) de nascimento da iniciativa e de cobertura atual? Qual é a principal plataforma?".

7 Disponível em: https://ninja.oximity.com/. Ao todo, o coletivo contabiliza até 2 mil integrantes, entre participações fixa se esporádicas, em todo o país.

8 Disponível em: http://azmina.com.brl. Acessado em 29 de março de 2017.

9 Disponível em: https://joma lista slivres.org/. Ac essa do em 29 de ma rço de 2017. 
desde o nível do indivíduo até o nível das relações sociais que definem uma comunidade. O modelo parte do princípio de que o jornalismo é construído socialmente, proposta que deriva da tradição norte-americana de estudos em newsmaking (TRAQUINA, 2012).

Uma vez assumida a impossibilidade de se produzir jornalismo totalmente livre de influências, o modelo teórico-metodológico de Shoemaker e Reese orienta análises sobre como e em que intensidade o jornalismo pode depender de fatores alheios a sua lógica própria. Em síntese, se o conteúdo é construído socialmente, para compreendê-lo é preciso estudar sua construção. Neste esforço, pode-se estudar quão dependente o noticiário é de:

1) Um sistema de crenças estabelecido em determinada sociedade, onde estão inseridas ideologia e cultura;

2) Instituições políticas e econômicas que desejam ver seus interesses representados no conteúdo levado a público;

3) Organizações de mídia e seus proprietários;

4) Rotinas organizacionais das redações;

5) Preferências pessoais do indivíduo jornalista.

Importante notar que cada uma dessas dimensões pode se desdobrar para descrever peculiaridades do jornalismo e de suas influências.

No entanto, o modelo dos autores, como toda proposição teórico-metodológica que delimita olhares sobre a realidade, não é suficiente para explicar toda a complexidade dos fenômenos jornalísticos. Isso é ainda mais verdadeiro quando tratamos de fenômenos novos que caracterizam o jornalismo pós-industrial (ANDERSON; BELL; SHIRKY, 2013).

No ecossistema midiático da segunda década do século XXI, as pessoas que trabalham dentro de uma redação jornalística produzem e publicam apenas uma fração do conteúdo em circulação (SINGER, 2013). Como "o poder e a influência dos editores sobre a pauta das notícias são inversamente proporcionais ao número de canais noticiosos disponíveis" (BRUNS, 2011, p. 121), e no ambiente pós-industrial o número de canais não para de crescer, autores como Bruns e Vu (2014) têm acusado a obsolescência do modelo, criado no ambiente de mídia tradicional.

Com isso, os usuários exercem força crescente com o apoio de tecnologias digitais, assumindo protagonismo que supera os limites do modelo de hierarquia das influências. 
Os jornalistas sempre foram influenciados pelos interesses da audiência, é claro - eles criam um produto que precisa de um mercado para sobreviver -, mas essa influência nunca foi tão direta, explícita e imediata como é agora" (SINGER, 2013, p. 67, tradução nossa).

Nas redações atuais, jornalistas têm acesso a um volume inédito de dados sobre comportamentos da audiência. É possível saber em tempo real, por exemplo, o número de usuários que visualizam uma notícia, quais tipos de histórias, formatos e mídias preferem, quais temas geram mais comentários e reações (VU, 2014). Com base nesses dados e após observar escolhas de editores e usuários, Lee, Lewis e Powers (2012) concluem que a audiência afeta mais as escolhas dos jornalistas do que o inverso. Em Canavilhas, Torres e Luna (2015), profissionais entrevistados no Brasil e em Portugal afirmam procurar o equilíbrio entre preferências do público e normas profissionais préexistentes. Tal balanceamento não parece tarefa simples, uma vez que as vontades dos usuários identificadas por meio dos números sinalizam melhores resultados econômicos (audiência, publicidade e assinaturas). E essas vontades podem colidir contra normas deontológicas da profissão cultuadas há décadas (BOCZOWSKI, MITCHELSTEIN e WALTER, 2010; SINGER, 2011).

Welbers (et al., 2015) apontam contradições entre discurso e prática de jornalistas holandeses. No estudo sobre cinco jornais daquele país, os pesquisadores identificaram que resultados expressivos de audiência coincidem com coberturas jornalísticas que se estendem. Ou seja, os temas que rendem cliques permanecem por mais tempo no noticiário. Porém, quando questionados sobre a influência das métricas no trabalho de seleção das notícias, os editores em geral as desprezam.

Anderson (2011) usou análise etnográfica para estudar jornalistas de 60 redações dos Estados Unidos e concluiu que os profissionais estão cedendo a autonomia profissional às métricas de audiência, e que esse processo é mais visível em equipes responsáveis por publicações nativas digitais. Nessas organizações, a cultura profissional está menos enraizada, enfatizando a dependência das vontades do público.

Em trabalhos mais recentes, Shoemaker e colegas (SHOEMAKER \& VOS, 2011; SHOEMAKER et al., 2010) reconhecem a ascensão da audiência como influência ao jornalismo, mas veem os usuários de notícias como "gatekeepers secundários", que podem tomar decisões sobre o conteúdo produzido e entregue pela mídia (compartilhar, recomendar, curtir). $\mathrm{Na}$ abordagem dos autores, as influências dos cidadãos sobre o 
conteúdo jornalístico caberiam na categoria das instituições sociais, dispersas entre outras forças. Para Lee, Lewis e Powers (2012), apesar de mais inclusiva, a revisão do modelo reforça o papel poderoso das mídias de massa no fluxo de informação.

$\mathrm{Na}$ verdade, o chamado jornalismo participativo (colaborativo ou ainda open source) tem envolvido os usuários em processos muito mais complexos do que simplesmente responder a estímulos dos jornalistas. Desde o início da década passada autores advertem para os efeitos de uma tendência à horizontalidade no diálogo entre profissionais e amadores (GILMOUR, 2004; BOWMAN, WILLIS, 2003). Iniciativas como Slashdot (MOURA, 2002), WikiNews, Kuro5hin (TRÄSEL, 2008) e OhMyNews (BRAMBILLA, 2006), entre outras, apontaram para possibilidades que, embora lentamente, vem sendo exploradas pelo jornalismo profissional.

À medida que o ambiente pós-industrial enfraquece a posição hegemônica dos profissionais, o conceito mercadológico de "audiência" passa a dar lugar a outro, o de "engajamento". A ideia de um jornalismo aberto à participação dos cidadãos, comumente associada ao desejo de uma sociedade plural, em que mais perspectivas estejam contempladas no debate público (GILMOUR, 2004; BOWMAN, WILLIS, 2003), são reincorporadas por um discurso em que a sustentabilidade econômica do jornalismo está em jogo (ROSENSTIEL, 2015). Um público engajado receberia melhor a ideia de contribuir financeiramente para pagar os custos da produção de informações, ou ainda pode ser mais valioso como audiência, uma vez que, é provável, está mais atento ao conteúdo (inclusive o de cunho publicitário). Daí surge uma série de novas questões sobre independência.

O jornalismo pode engajar os usuários sem ele próprio envolver-se com os interesses dos usuários? É possível garantir que, atuando com um público engajado, os jornalistas tomem decisões somente de acordo com a sua própria lógica (KARPPINEN e MOE, 2016)? Provavelmente, não.

Mas também neste caso deve-se prestar atenção à natureza e à força exercida pela influência dos cidadãos. Para endereçar tais questões, o modelo da hierarquia das influências pode ainda ser útil, mas desde que os usuários, quando alçados a tomar decisões editoriais, sejam promovidos à condição de sujeitos ativos. Talvez o desenvolvimento de sistemas participativos mais abertos, a exemplo da plataforma norte- 
americana Hearken ${ }^{10}$, naturalmente venha a exigir uma sexta categoria de influências, inteiramente dedicada às forças exercidas pelos usuários sobre o conteúdo.

Pesquisas que se proponham a desvendar esse novo problema relacionado à independência inevitavelmente terão de enfrentar situações em que os interesses da audiência se desalinham em relação aos padrões éticos dos jornalistas. Nestes casos, os jornalistas teriam de garantir independência de quem justifica sua existência profissional: seus públicos.

\section{Considerações finais}

O percurso trilhado até aqui permitiu que revisitássemos cruzamentos conceituais importantes para a determinação do terreno da independência jornalística. Em alguns aspectos, tais encontros cristalizam arestas que ajudam a sustentar planos mais sofisticados na abstração dessa ideia. Sabemos que a independência é um valor jornalístico relevante, que ele desafia o tempo e resiste às mutações que o campo sofre, e que é reivindicado por diversos atores, distintos em seus graus de autonomia, em suas origens de financiamento e em seus comprometimentos políticos. Se no Brasil, a ideia de mídia pública é a virtualidade do meio independente - afinal, não estaria nem nas mãos do Estado nem da iniciativa privada -, na Europa, independentes são os meios privados financiados por anunciantes mas desatrelados dos governos.

As características dos empreendimentos jornalísticos que se autointitulam independentes na atualidade revelam ainda um alto grau de idealização em torno dessa categoria, o que contribui para uma certa fetichização dessa condição. De igual monta, percebe-se ainda uma evidente fragilidade financeira da maior parte dessas iniciativas, o que as leva a buscar soluções de sustentabilidade que também não garantem a plenitude na autonomia, embora contem com maior liberdade editorial. Os próximos anos poderão nos responder se tais saídas financeiras são as mais formidáveis para esses meios, e se sua consolidação tornará mais nítido um modelo alternativo de mídia.

10 Hearken é uma empresa que desenvolve softwares para pequenas redações dos Estados Unidos produzirem reportagens com o a uxilio das comunidades em que estão inseridas. Ma is informações em: https://www.wea rehea rken.com. 
Enquanto isso não acontece, mais prudente é revisitar periodicamente os limites do perímetro conceitual da independência. Palmilhar a área significa também conjugar a noção numa perspectiva mais relacional. Isto é, independência, liberdade e autonomia não se definem de forma isolada, mas na tensão com seus opostos. Só se pode afirmar que um meio é independente se observarmos seus contextos: ele depende menos do Estado do que de seus anunciantes em tal situação, e demonstra mais autonomia editorial em tal momento. No episódio seguinte, essa condição pode se alterar drasticamente.

À guisa de conclusão, as noções perseguidas são menos tangíveis do que ansiávamos, porém mais dinâmicas, mutáveis e adaptáveis aos contextos. Se for de intensas disputas políticas, a correlação de forças contribuirá para que emerja uma ideia em que independência será a afirmação do não alinhamento ao poder hegemônico. Se o contexto for de competitividade comercial, poderá vir à tona uma ideia em que ser independente é ser livre o suficiente para contrariar interesses econômicos. Se o contexto for mais complexo, de fricção constante entre camadas do público consumidor/colaborador, aí será necessário construir um modelo de independência que não ceda à tentação de vocalizar a "vontade da maioria" - como na democracia - nem a que atenda apenas àqueles que "decidem porque estão pagando as contas". Como se pode ver, os desafios na planície da independência jornalística não cessam.

\section{Referências}

ANDERSON, C. W.; BELL, E.; SHIRKY, C. O jornalismo pós-industrial: Adaptação aos novos tempos. Revista de Jornalismo Espm, São Paulo, p.30-89, abr. 2013.

ATTON, C. Alternative Media. London: Sage, 2002.

BAHIA, J. Jornal, história e técnica. 5. ed., rev. e aum. Rio de Janeiro: Mauad X, 2009.

BECKER, M. L. Mídia alternativa: antiempresarial, anti-industrial, anticapitalista?. In.: WOITOWICZ, Karina Janz (Org.). Recortes da mídia alternativa: histórias \& memórias da comunicação no Brasil. Ponta Grossa: Ed. UEPG, 2009.

BELTRÃO, L. Iniciação a filosofia do jornalismo. 2. ed. São Paulo: EDUSP, 1992.

BRAMBILLA, A. M. Jornalismo open source: discussão e experimentação do Oh my News International. 2006. 248 f. Dissertação (Mestrado) - Curso de Comunicação, Universidade Federal do Rio Grande do Sul, Porto Alegre. 
BRUNS, A. Gatekeeping, gatewatching, realimentação em tempo real: Novos desafios para o Jornalismo. Brazilian Journalism Research, Brasília, v. 7, n. 11, p.119-140, 2011. Disponível em: <https://bjr.sbpjor.org.br/bjr/article/view/342>. Acesso em: 28 nov. 2016.

$\mathrm{BUCCl}$, E. A imprensa e o dever de liberdade: a independência editorial e suas fronteiras com a indústria do entretenimento, as fontes, os governos, os corporativismos, o poder econômico e as ONGs. São Paulo: Contexto, 2009.

CAGÉ, J. Salvar os media: Capitalismo, Financiamento Participativo e Democracia. Lisboa: Círculo de Leitores, 2009.

DOWNING, J. Radical Media: rebellious communication and social movements. Thousand Oaks: Sage, 2001.

FUCHS, C.; SANDOVAL, M. Towards a critical theory of alternative media. Disponível em: http://fuchs.uti.at/wp-content/uploads/2009/12/alt media.pdf. Acesso em: 17 fev 201.

KARPPINEN, K.; MOE, H. What we talk about when talk about "Media Independence". Javnost - The Public, v. 23, n. 2, p.105-119, 2 abr. 2016.

LEE, A. M.; LEWIS, S. C.; POWERS, M. Audience Clicks and News Placement: A Study of Time-Lagged Influence in Online Journalism. Communication Research, v. 41, n. 4, p.505-530, 20 nov. 2012.

LIMA, V. Liberdade de Expressão x Liberdade de Imprensa: direito à comunicação e democracia. São Paulo: Publisher Brasil, 2010.

MOURA, C. Jornalismo na era Slashdot. Biblioteca Online de Ciências da Comunicação, 2002. Disponível em: < http://www.bocc.ubi.pt/pag/moura-catarinajornalismo-slashdot.pdf >. Acesso em 30 jun. 2016.

SCHULZ, W. Approaches to independence. In: SCHULZ, W; VALCKE, P. \& IRION, K. The Independence of the Media and its Regulatory Agencies: Shedding New Light on Formal an Actual Independence against the National Context. Bristol, Editora Intellect, Reino Unido, 2013.

SHOEMAKER, P. J. et al. Os leitores como gatekeepers das notícias on-line: Brasil, China e Estados Unidos. Brazilian Journalism Research, Brasília, v. 6, n. 1, p.58-83, 2010.

SHOEMAKER, P. J.; REESE, S. D. Mediating the message in the 21st century: A media sociology perspective. 3. ed. Nova York: Routledge, 2013.

SHOEMAKER, P. J.; VOS, T. P. Teoria do gatekeeping: Seleção e construção da notícia. Porto Alegre. Penso, 2011.

SINGER, J. B.. User-generated visibility: Secondary gatekeeping in a shared media space. New Media \& Society, v. 16, n. 1, p.55-73, 15 mar. 2013.

SINGER, J. B. et al. Participatory Journalism: Guarding open gates at online newspapers. Chichester: Wiley-blackwell, 2011. 227 p.

SINGER, J. B. Community Service: editor pride and user preference on local newspaper websites. Journalism Practice, [s.I.], v. 5, n. 6, p.623-642, dez. 2011. 
TRAQUINA, N. Teorias do jornalismo: Porque as notícias são como são. 3. ed. v. 1. Florianópolis: Insular, 2012.

TRÄSEL, M. Jornalismo participativo online: intervenção do público no Wikinews e no Kuro5hin. Brazilian Journalism Research. Brasília, v. 1, n.1, p. 77-96, 2008. Disponível em: <https://bjr.sbpjor.org.br/bjr/article/view/165/164>. Acesso em: 31/8/2016.

$\mathrm{VU}, \mathrm{H}$. T. The online audience as gatekeeper: The influence of reader metrics on news editorial selection. Journalism,[s.I.], v. 15, n. 8, p.1094-1110, 28 out. 2013.

WOITOWICZ, K. J. Diálogos entre folkcomunicação e mídia alternativa: um passeio teórico pelas formas de comunicação dos grupos marginalizados. Razón y Palabra, v. 3, p. 1-15, 2011. 